\title{
Assessment of phobic patients
}

DEAR SIR

We have developed an extensive computerised assessment 'interview' for patients with phobic problems. By collecting data on patients at the start of treatment it will eventually be possible, in the light of their subsequent progress, to identify variables predicting to which type of behavioural treatment each patient is most likely to respond.

Anyone treating phobic patients in the Greater London area is invited to refer them to us for a single interview near the start of treatment. In return we shall be happy to provide printed summaries of the assessments obtained, and will ask for permission to make a brief progress assessment after treatment is completed.

Any therapist desiring further details is welcome to visit us here by arrangement.

\section{Institute of Psychiatry \\ De Crespigny Park \\ London SES $8 A F$}

A. CARR
A. GHOSH
R. ANCILL

Clinical Computer Group

\section{News Items}

\section{Howard C. White Memorial Fund}

Dr Howard White, Senior Consultant Psychiatrist at Queen Elizabeth, Birmingham General and Midland Nerve Hospitals died on 17 April 1980. His colleagues and friends would like to remember him by sponsoring an annual lecture in the programme of the Birmingham Medical Institute Section of Psychiatry and by planting a tree in the gardens of the Midland Nerve Hospital. Those who would like to contribute should send their donations to: Mr S. Rich, Unit Administrator, Midland Nerve Hospital, Elvetham Road, Birmingham B15 2NJ.

\section{Information needed}

In 1979 the Association for Child Psychology and Psychiatry published a Directory of School Psychological and Child Guidance Services. Unfortunately much of the information it contained was inaccurate and the Committee of the

\section{Recruitment to mental handicap}

DeAR SiR,

I would like to endorse the sentiments expressed in the letter in the Bulletin (July 1980, p. 108) from Dr Agnes Hauck of the Glenfrith Hospital, Leicester. A three-month rotation into mental handicap is nowhere near long enough to give anybody with interest in psychiatry a leaning towards mental handicap, nor is it long enough for anyone to learn the various facets of the subject. There should be at least a six-month block, for all rotational registrars going into mental handicap or child psychiatry.

It is obvious from the advertisements in the $B M J$ and Lancet, that to recruit into either mental handicap or child psychiatry the jobs are now being mixed part-time, i.e. 50 per cent in each, or even in general psychiatry.

I do hope that note will be taken of this, and that $\mathrm{Dr}$ Hauck's opinion will be formalized.

Middlewood Hospital

JOSEPHINE COOPER

Sheffield S6 ITP Consultant Psychiatrist
ACPP decided to write to all known clinics, services and voluntary organizations throughout the UK and BAOR in an attempt to gain accurate information. Only half of the 923 proformas have been returned, and the Committee asks all psychiatrists if they would check with their clinic administrator that the form has been received and returned-even if it contained correct information. All enquiries and replies may be sent to: Mrs Carol Howie, Assistant Secretary, $15 \mathrm{St}$ Justin Close, St Pauls Cray, Kent BR5 3LU.

\section{Professor A. V. Snezhnevsky}

Dr A. V. Snezhnevsky, Professor of Psychiatry at the Academy of Medical Sciences in Moscow, has resigned from his Corresponding Fellowship of the College. Council had invited him to answer criticisms of his psychiatric practice as it related to Russian citizens said to be political dissenters, and in his reply he submitted his resignation.

Printed in Great Britain by Headley Brothers Ltd The Invicta Press Ashford Kent and London 